\title{
Structural Insights Into Bioactive Thiazolidin-4-one: Experimental and Theoretical Data
}

\author{
Marcos Veríssimo de Oliveira Cardoso ${ }^{\mathrm{a}^{*}}$, Marcelo Zaldini Hernandes ${ }^{\mathrm{a}}$, Diogo Rodrigo Magalhães \\ Moreira ${ }^{\mathrm{b}}$, Frederico José de Santana Pontes ${ }^{\mathrm{c}}$, Carlos Alberto de Simone ${ }^{\mathrm{d}}$ and \\ Ana Cristina Lima Leite ${ }^{\mathrm{a}}$
}

\begin{abstract}
${ }^{a}$ Departamento de Ciências Farmacêuticas, Centro de Ciências da Saúde, Universidade Federal de Pernambuco, 50740-540, Recife, PE, Brazil; ${ }^{b}$ Centro de Pesquisas Gonçalo Moniz, Fundação Oswaldo Cruz, CEP 40296-750, Salvador, BA, Brazil; ' Departamento de Química Fundamental, Centro de Ciências Exatas e da Natureza, Universidade Federal de Pernambuco, 50740-540, Recife, PE, Brazil; ' Departamento de Física e Informática, Instituto de Física,Universidade de São Paulo, CEP 13560-970, São Carlos, SP, Brazil
\end{abstract}

Received June 09, 2014: Revised January 13, 2015: Accepted January 27, 2015

\begin{abstract}
Although viewed as promising drug candidates, few efforts have been addressed towards the structural chemistry of 2-hydrazonothiazolidin-4-ones. Therefore, 2-[(3-phenylsulfanylpropylidene)-hydrazono]thiazolidin-4-one (ATZ3) was synthesized and its crystal and molecular structure was studied by NMR and X-ray single crystal diffraction. The ${ }^{1} \mathrm{H}$ NMR spectral data indicated that the hydrazone group assumes the $E$ configuration, which was further confirmed by bi-dimensional NMR and crystallographic data. Despite agreement between most bond lengths and angleswith their expected values, the crystalline packing provided important information with regard to the double bond position involving the C-4 carbon. Quantum chemical calculations at Semiempirical, Density Functional Theory (DFT) and Ab Initio levels provided a good agreement between calculated and structural results provided by X-ray analysis. The system's dimerization energies were also estimated. Statistical and Hierarchic Cluster Analysis (HCA) revealed interesting aspects of the calculations and pointed to the B3LYP as the most accurate in the determination of structure among the methods considered, in spite of some good results achieved by semiempirical schemes.
\end{abstract}

Keywords: Thiazolidin-2-ones, hydrazones, thiazole, x-ray, quantum chemical.

\section{INTRODUCTION}

Highly functionalized thiazole, thiazolidin-4-one and thiazolidine-2,4-diones derivatives have been explored as potential drug candidates [1-6], some of which have entered in clinical trials [7]. Following this promising line of research, our group has been deeply involved in the medicinal chemistry of thiazolidin-4-one derivatives as potential antiparasitic drug candidates $[4,8-10]$. Our biological studies have proven thiazolidin-4-ones are inhibitors of parasitic cysteine proteases [4,9-12]. To advance our medicinal chemistry program, in silico studies through molecular docking have also been performed to highlight the binding mode of these inhibitors into the protease's active site $[4,8,9]$. A precise structural and molecular knowledge for this chemical class is highly desirable, to improve the accuracy of our molecular docking and subsequently the quality of our drug design program.

Although there is a plethora of crystallographic structures available for thiazolidine-2,4-diones and 1,3-thiazoles, similar information for thiazolidin-4-one bearing a hydrazone moiety is much less abundant $[13,14]$. Likewise, 2-hydrazonothiazolidin-4-ones can result to isomers and

*Address correspondence to this author at the Universidade Federal de Pernambuco, Departamento de Ciências Farmacêuticas, Recife, PE, Brazil; Tel: +55812126 8511; Fax: +558121268510;

E-mail: marcosvocardoso@gmail.com tautomers (Fig. 1) but chemical aspects regarding these features have rarely been discussed [15]. The structural chemistry and molecular modelling towards this chemical class is thereby chemically relevant.

In order to address these issues, studies of spectroscopy, X-ray diffractometry, and computational chemistry were gathered for a highly representative bioactive thiazolidin-4one, named ATZ3 [10] (Fig. 1). More specifically, we collected semiempirical and quantum chemistry calculations at different levels of theory that were performed for this compound, along with a comparison of the intermolecular interactions collected from the X-ray crystallography and the gasphase isolated molecule. Original NMR data was acquired and studied. These findings resulted in relevant molecular insights, which could be useful for anyone working on thiazole chemistry.

\section{RESULTS AND DISCUSSION}

\subsection{Conformational Analysis}

ATZ3 was essentially synthesized as previously reported [10] and detailed in Scheme 1, with a moderate yield (53\%). The structure of the ATZ3 was initially ascertained by comparison of its previously reported melting point data and infrared spectra [10]. The present work contains original 


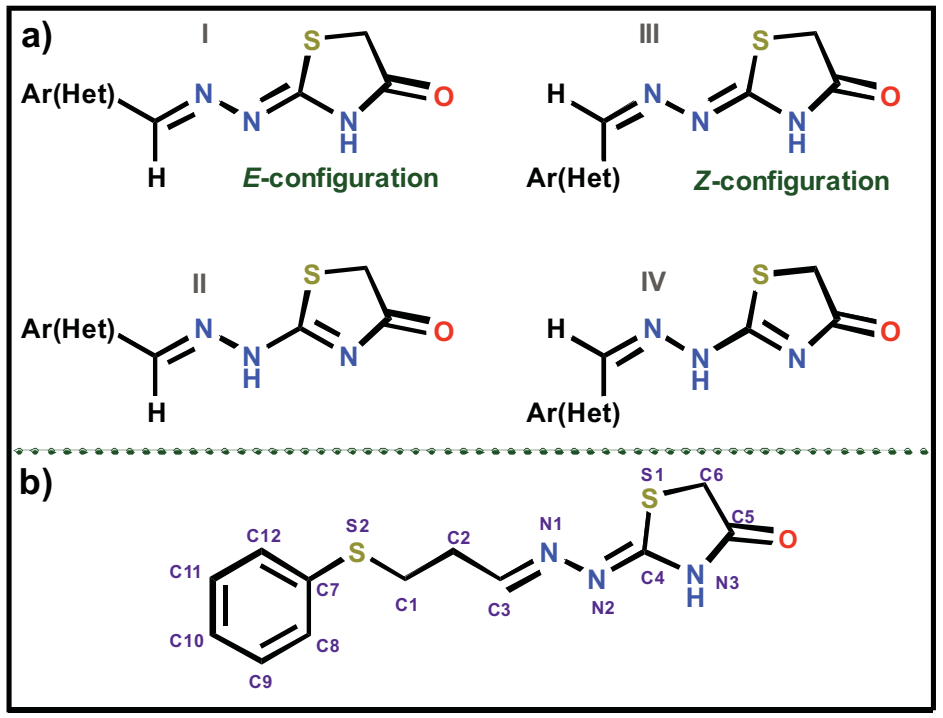

Fig. (1). a) Most representative isomers and tautomers. b) Numbered structure of the hydrazonethiazolidin-4-one (ATZ3) under study.

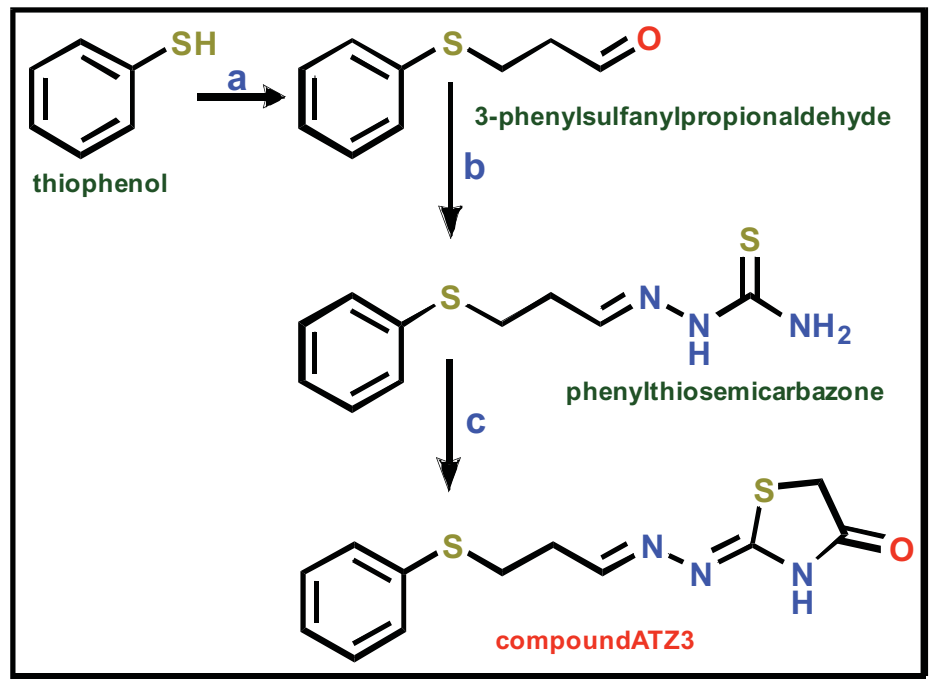

Scheme 1. Synthesis of compound ATZ3. Reagents and conditions: (a) i) 3-bromopropionaldehyde dimethyl acetal, $\mathrm{KOH}$, fusion at $110^{\circ} \mathrm{C}$; 2 h; ii) Water, sulfuric acid, reflux, 1h; (b) thiosemicarbazide, $\mathrm{MeOH}, \mathrm{AcOH}$, reflux, 12 h. (c) bromoacetic acid, AcONa, EtOH, reflux, 8 h.

examinations of the high-resolution mass spectra (HR-MS) and NMR $\left({ }^{1} \mathrm{H},{ }^{13} \mathrm{C}\right.$ and DEPT $)$ spectral.

The first step of this work was to determine the relative configuration of the exocyclic iminic bond (Fig. 1a). The ${ }^{1} \mathrm{H}$ NMR spectra showed a triplet at $\delta 7.72$ for one proton, suggesting the presence of only one isomer. This was further confirmed by HPLC chromatogram. Although Karabatsos [16] had stated that iminic hydrogen of $(E)$-diastereomer usually is downfielded rather than the analogous hydrogen in $(Z)$-diastereomer, this kind of assignment using onedimensional ${ }^{1} \mathrm{H}$ NMR alone is feasible of mistake, because of the influence of the solvent used and the chemical nature of substituents around the imine-attached hydrogen. Evidence was gathered about the relative configuration of the imine double bond. Moreover, NH proton resonated at 11.78 ppm, which is suggestive of a lactam proton (I) rather than an imine-like proton (II), the latter being expected to resonate at much upfield. This chemical field might be influ- enced by solvent effect, but X-ray analysis has corroborated this assessment.

The Ortep-3 diagram displays the entire molecular structure conformation obtained from X-ray analysis for the compound ATZ3 (Fig. 2). The crystal data details are summarized in Table $\mathbf{1}$.

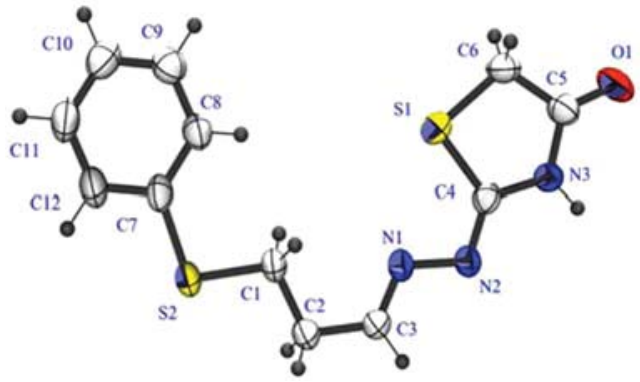

Fig. (2). ORTEP-3 diagram of the ATZ-3. Displacement ellipsoids are drawn at $50 \%$ probability level. 
Table 1. Crystal data and structure refinement.

\begin{tabular}{|c|c|}
\hline Empirical formula & $\mathrm{C}_{12} \mathrm{H}_{13} \mathrm{~N}_{3} \mathrm{OS}_{2}$ \\
\hline Formula weight & 279.37 \\
\hline Temperature (K) & $295 \mathrm{~K}$ \\
\hline Wavelength $(\AA)$ & $0.71073 \AA$ \\
\hline Crystal system & Monoclinic \\
\hline Space group & $\mathrm{P} 2{ }_{1} / \mathrm{c}$ \\
\hline \multicolumn{2}{|l|}{ Unit cell dimensions } \\
\hline$a(\AA)$ & $13.5930(7)$ \\
\hline$b(\AA)$ & $5.6310(3) \quad \beta=128.042(3)$ \\
\hline$c(\AA)$ & $21.6040(7)$ \\
\hline Volume $\left(\AA^{3}\right)$ & $1302.32(11)$ \\
\hline Z & 4 \\
\hline$\rho_{\text {calc }}\left(\mathrm{g} \mathrm{cm}^{-3}\right)$ & $1.425 \mathrm{Mg} / \mathrm{m}^{3}$ \\
\hline$\mu\left(\mathrm{mm}^{-1}\right)$ & $0.406 \mathrm{~mm}^{-1}$ \\
\hline $\mathrm{F}(000)$ & 584 \\
\hline Crystal size (mm) & $0.150 \times 0.132 \times 0.099$ \\
\hline$\theta$ range $\left(^{\circ}\right)$ & 3.0 to 26.6 \\
\hline Reflections collected & 9401 \\
\hline Independent reflections & 2709 \\
\hline$R_{\text {int }}$ & 0.064 \\
\hline Refinement method & Full-matrix least-squares on $\mathrm{F}^{2}$ \\
\hline Computing & $\begin{array}{c}\text { COLLECT, HKL Denzo and } \\
\text { Scalepack SHELXS-97, } \\
\text { SHELXL-97 }\end{array}$ \\
\hline Data / restraints / parameters & $2007 / 0 / 163$ \\
\hline Goodness-of-fit on $\mathrm{F}^{2}$ & 1.029 \\
\hline$R[\mathrm{I}>2 \sigma(I)]$ & 0.064 \\
\hline$w R_{2}$ (all data) & 0.110 \\
\hline Residual extrema (e $\AA^{-3}$ ) & 0.275 and -0.227 \\
\hline
\end{tabular}

Bond lengths and bond angles of the structures are essentially in agreement with expected values, in particular, those found among the thiazolidine rings as reported in the Cambridge Structural Database [17]. The atoms of the thiazolidine ring and the linkage of the atoms N2,N1,C3,C2,C1 and $\mathrm{S} 2$ are planar and the largest deviation $(0.0864 \AA)$ from the least-square plane is exhibited by atom $\mathrm{C} 5$. The dihedral angle between this plane and the aromatic ring is $10.6^{\circ}$. The molecular packing involves one strong intermolecular hydrogen contact between $\mathrm{N} 3-\mathrm{H} 1 \cdots \cdot \mathrm{N} 2^{\mathrm{i}}$ where $\mathrm{H} 1 \cdots \cdots \mathrm{N} 2^{\mathrm{i}}=$ $1.869(2) \AA ; \mathrm{N} 3 \cdots \cdot \mathrm{N} 22^{\mathrm{i}}=2.867(3) \AA$ and $\mathrm{N} 3-\mathrm{H} 1 \cdots \cdots \mathrm{N} 2^{\mathrm{i}}=174^{\circ}$ $[\mathrm{i}=-\mathrm{x},-\mathrm{y}+1,-\mathrm{z}+2]$, as can see in Fig. (3).

$\mathrm{X}$-ray diffraction is one of the most precise and widely used methods for the determination of the position of atoms in molecules and solids. However, the correct location of hydrogen atoms is nearly always determined by geometric considerations or indirect methods. Doubt about a molecular geometry obtained from the X-ray analysis can be alleviated with help of quantum chemical investigations.

The possibility of incorrect attribution of hydrogen atom position in the analyzed structure was investigated in this work. An alternative tautomeric form of the proposed thiazolidine was studied using quantum chemical methods. The proposed tautomeric form of the molecule are exposed on (Fig. 4). We have analyzed energetic (Table 2) and structural factors (Tables 3 and $\mathbf{4}$ ) to decide, which structure are the most stable.

All calculations concerning the relative stability of this tautomeric form indicates it as the less stable specie in comparison to the first proposed structure. (see Table 2). Energy differences between the species are estimated up 10 kcal.mol ${ }^{-1}$ by the semiempirical calculations (AM1, RM1, MNDO, MNDO/d, PM3, PM6), while the most sophisticated methods (HF, MP2, B3LYP) predict a value between 4 to 6 $\mathrm{kcal}^{\mathrm{mol}} \mathrm{l}^{-1}$. Electronic correlation effects included through the MP2 calculation are negligible in comparison to the HF result, whereas the B3LYP prediction points a smaller energetic difference between the tautomers.

Comparing the performance from the methods in reproducing the two proposed geometries, it may be possible to observe that errors originated from the Tautomer (2) (Table 4), in general, are almost always bigger than those obtained from the Tautomer (1) (Table 3). This evidence reinforces the correctness from the initially proposed structure. Extensive information about the optimized geometries is enclosed in the supplementary material (Tables $\mathbf{S 1}-\mathbf{S 6}$ ).

The first stage of analysis from the geometric parameters produced by quantum chemical methods had the Average Unsigned Error (AUE) as an indicator stronger than Average Error (AE), for evaluation of the computational performance. Conclusions based in the AUE results show to be more trustworthy due the impossibility of error cancelation to mask the analysis. Standard Deviation (SD) indicates how close to the mean value calculated data are. Low value for SD indicates that the data points tend to be close to the mean, whereas high SD indicates that the data spreads over a large range of values.

Concerning the Tautomer (1) structure (see Table 3), the AUE measurement assures that HF has the best performance for bond lengths among the considered methods. MP2 gives smaller error than the B3LYP method. Among the semiempirical methods, MNDO has the largest error for bond lengths, and the inclusion of $d$ orbitals in its more recent implementation $(\mathrm{MNDO} / \mathrm{d})$ was unable to correctly predict the structures. PM6 and RM1 methods had performances comparable to the B3LYP.

While the inclusion of electronic correlations seems to not be very important to bond length results, the statistical analysis indicated that for bond and torsional angles predictions, correlation effects are indispensable for a good reproducing of these parameters. B3LYP had the smallest errors and may be considered the best method to reproduce the experimental geometry considering the entirety of studied parameters. 


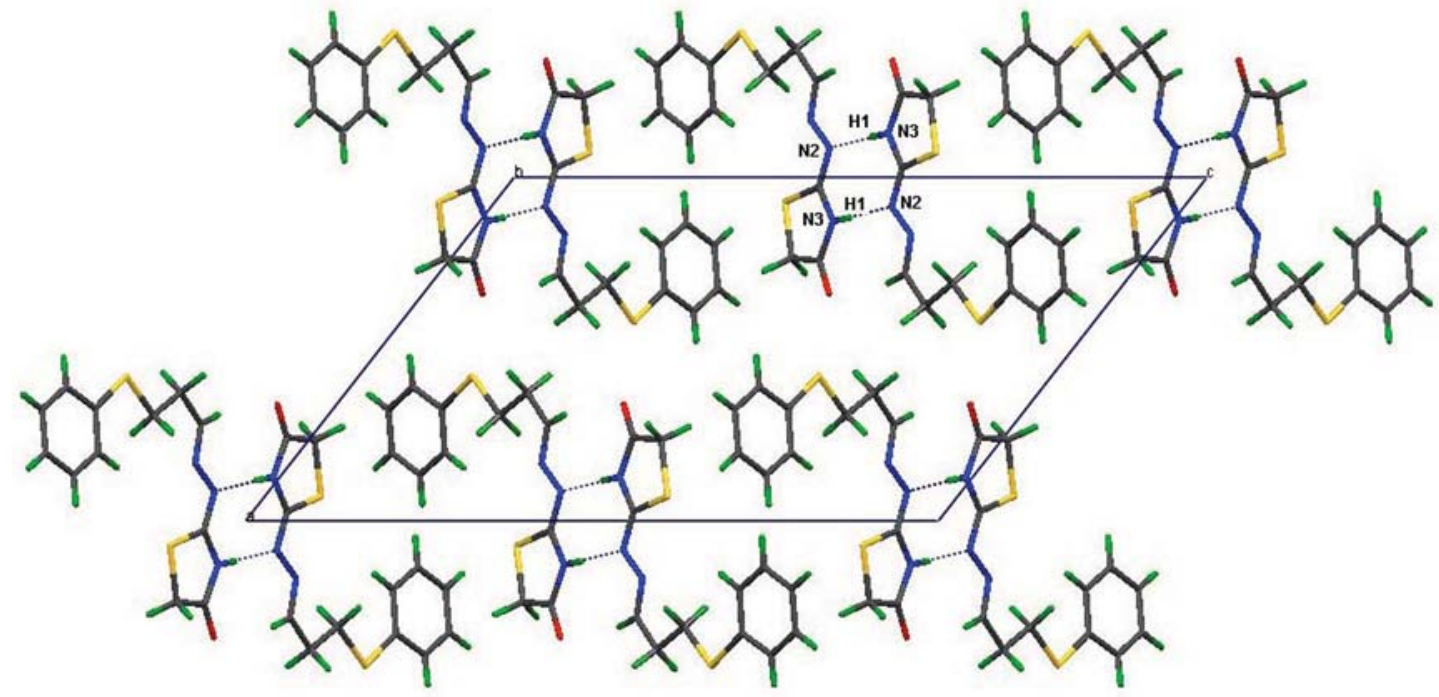

Fig. (3). Packing diagram of compound ATZ3.

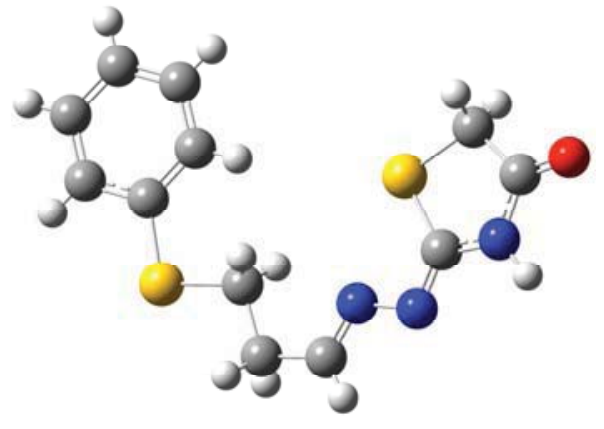

Tautomer (1)

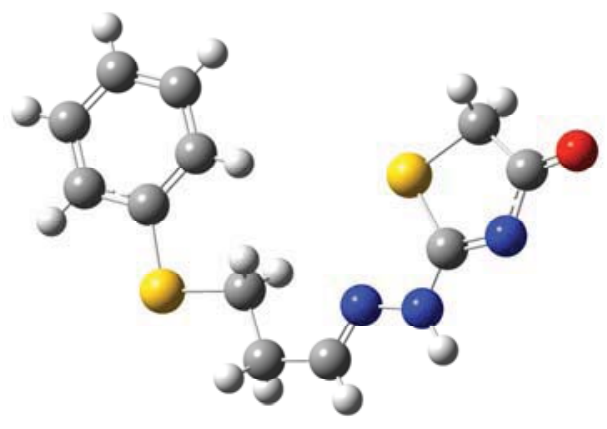

Tautomer (2)

Fig. (4). Two proposed structures studied in the quantum chemical study. Left Tautomer (1), structure derived from X-ray analysis and right Tautomer (2), an alternative tautomer, which proves to be less stable than Tautomer (1).

Table 2. Relative energies (in kcal.mol ${ }^{-1}$ ) predicted by different quantum chemical methods for Tautomer (1) and Tautomer (2).

\begin{tabular}{|c|c|c|c|c|c|}
\hline Method & Tautomer (1) & Tautomer (2) & Method & Tautomer (1) & Tautomer (2) \\
\hline \hline HF & 0.0 & +6.66 & MNDO & 0.0 & 0.0 \\
\hline MP2 & 0.0 & +6.36 & MNDO/d & 0.0 & 0.0 \\
\hline B3LYP & 0.0 & +4.64 & PM3 & & +16.09 \\
\hline AM1 & 0.0 & +13.81 & & & +11.50 \\
\hline RM1 & 0.0 & +13.01 & & \\
\hline
\end{tabular}

The expected superior performance of RM1 in comparison to AM1 was observed. RM1 showed good results in predicting this geometry, in comparison with other recent and very accurate semiempirical parameterizations, like the PM6 method. PM3 method gave the best results for torsional angles among the semiempirical methods, contrasting with the large deviation provided by PM6 method.

One can observe a question addressed to the performance of B3LYP and MP2 regarding the computational requirements to carry out calculations of these methods and the associated results provided by them. MP2 method is the first choice to include electronic correlation in a calculation by an $a b$ initio way. However, the high computational effort to complete a MP2 calculation restricts its applications to deal with real chemistry problems. On the other hand, B3LYP method is a parameterized hybrid exchange-correlation functional, which has been widely used in computational chemistry applications. Mainly due its parametrization, the B3LYP method combines an acceptable computational demand with related good results, showing a good overall performance when compared with other more traditional methods, like MP2, for example. Additionally, Ab Initio and DFT calcula- 
Table 3. Statistical measurements summary (AE, AUE and SD) from the comparison of the bond lengths ( $\AA$ ), bond and torsional angles $\left({ }^{0}\right)$ between experimental and several theoretical methods for the Tautomer (1).

\begin{tabular}{|c|c|c|c|c|c|c|c|c|c|}
\hline & HF & B3LYP & MP2 & AM1 & MNDO & MNDO/d & PM3 & PM6 & RM1 \\
\hline \multicolumn{10}{|c|}{ Bond Lengths (Å) } \\
\hline $\mathrm{AE}$ & 0.005 & 0.018 & 0.016 & 0.003 & 0.006 & 0.023 & 0.016 & 0.019 & 0.014 \\
\hline AUE & 0.012 & 0.020 & 0.017 & 0.028 & 0.040 & 0.030 & 0.023 & 0.022 & 0.019 \\
\hline SD & 0.016 & 0.013 & 0.011 & 0.035 & 0.044 & 0.027 & 0.026 & 0.021 & 0.020 \\
\hline \multicolumn{10}{|c|}{ Bond Angles ( ${ }^{\circ}$ ) } \\
\hline $\mathrm{AE}$ & 0.31 & 0.32 & -0.14 & 0.78 & 0.73 & 0.73 & 0.76 & 0.34 & 0.01 \\
\hline AUE & 1.63 & 1.18 & 1.50 & 2.08 & 2.47 & 2.40 & 2.60 & 2.08 & 2.02 \\
\hline $\mathrm{SD}$ & 2.20 & 1.53 & 2.08 & 2.78 & 3.43 & 3.40 & 3.90 & 2.73 & 2.52 \\
\hline \multicolumn{10}{|c|}{ Torsional Angles ( $\left(^{\circ}\right)$} \\
\hline $\mathrm{AE}$ & 0.1 & -0.3 & 0.1 & -7.0 & 3.5 & 3.7 & 0.2 & -7.9 & -1.2 \\
\hline AUE & 7.6 & 2.3 & 6.2 & 8.6 & 11.1 & 10.5 & 2.8 & 10.8 & 4.7 \\
\hline SD & 23.3 & 4.2 & 18.6 & 34.9 & 30.4 & 28.7 & 3.7 & 36.0 & 11.3 \\
\hline
\end{tabular}

Table 4. Statistical measurements summary (AE, AUE and SD) from the comparison of the bond lengths ( $\AA$ ), bond and torsional angles $\left({ }^{\circ}\right)$ between experimental and several theoretical methods for the Tautomer (2).

\begin{tabular}{|c|c|c|c|c|c|c|c|c|c|}
\hline & HF & B3LYP & MP2 & AM1 & MNDO & MNDO/d & PM3 & PM6 & RM1 \\
\hline \multicolumn{10}{|c|}{ Bond Lengths ( $\AA$ ) } \\
\hline $\mathrm{AE}$ & 0.004 & 0.017 & 0.014 & 0.008 & 0.009 & 0.026 & 0.021 & 0.015 & 0.014 \\
\hline AUE & 0.020 & 0.029 & 0.026 & 0.035 & 0.046 & 0.036 & 0.027 & 0.031 & 0.026 \\
\hline SD & 0.029 & 0.029 & 0.029 & 0.043 & 0.052 & 0.038 & 0.035 & 0.038 & 0.033 \\
\hline \multicolumn{10}{|c|}{ Bond Angles ( ${ }^{\circ}$ ) } \\
\hline $\mathrm{AE}$ & 0.32 & 0.33 & -0.08 & 0.58 & 0.31 & 0.33 & 0.54 & 0.39 & -0.11 \\
\hline AUE & 2.76 & 2.44 & 2.78 & 2.30 & 2.33 & 2.26 & 2.22 & 1.94 & 2.30 \\
\hline SD & 3.88 & 3.77 & 4.06 & 3.31 & 3.01 & 2.93 & 2.99 & 2.62 & 3.04 \\
\hline \multicolumn{10}{|c|}{ Torsional Angles $\left({ }^{\circ}\right)$} \\
\hline $\mathrm{AE}$ & 0.1 & -0.5 & 0.1 & -0.6 & 3.1 & 3.2 & -0.4 & -4.3 & -1.3 \\
\hline AUE & 7.6 & 3.5 & 6.3 & 3.5 & 14.1 & 13.8 & 4.0 & 6.6 & 4.9 \\
\hline SD & 23.4 & 7.8 & 19.0 & 5.5 & 32.0 & 31.4 & 7.5 & 21.4 & 11.8 \\
\hline
\end{tabular}

tions need much more memory resources from the computer. In summary, semiempirical methods can be a good exploratory tool for calculations of geometry and energy of this kind of system with a low computational cost and moderate accuracy.

\subsection{Hierarchical Cluster Analysis (HCA) from the Geometry Optimization Results}

With the large amount of geometric parameters to analyze, it becomes almost impossible to observe a possible pattern in the calculated data without the use of multivariate statistical tools. Successful applications of exploratory statistical tools to analyze geometric parameters obtained from quantum chemical calculation [18] encouraged us to apply similar techniques in our work. The HCA analysis used here allowed for the easy identification of graphic patterns through use of a dendogram.

Using the single linkage method for the clustering associated to a Euclidian metric, HCA analyses were carried out on the geometric parameters produced by the theoretical 
(a)

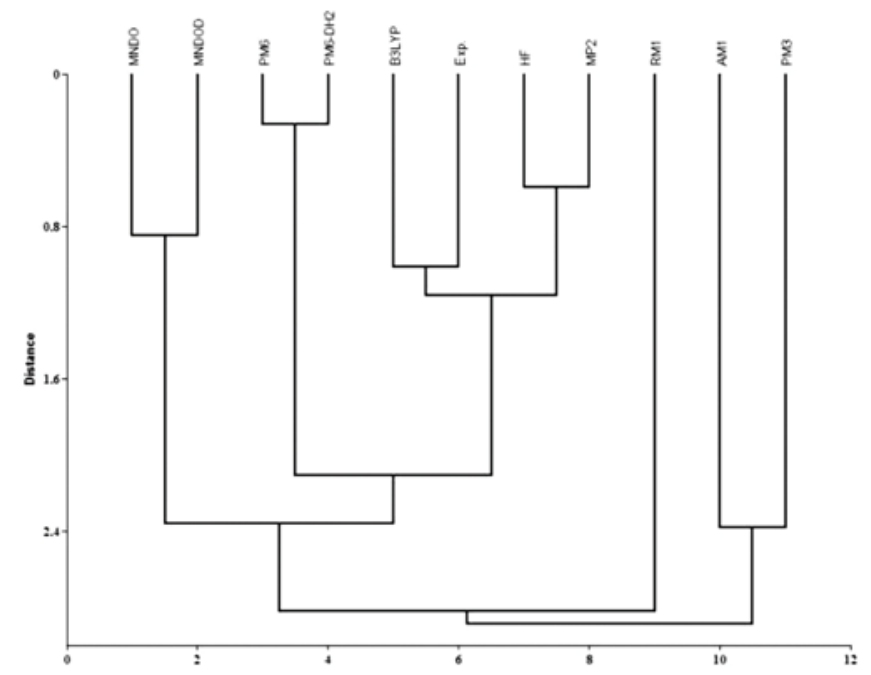

(c)

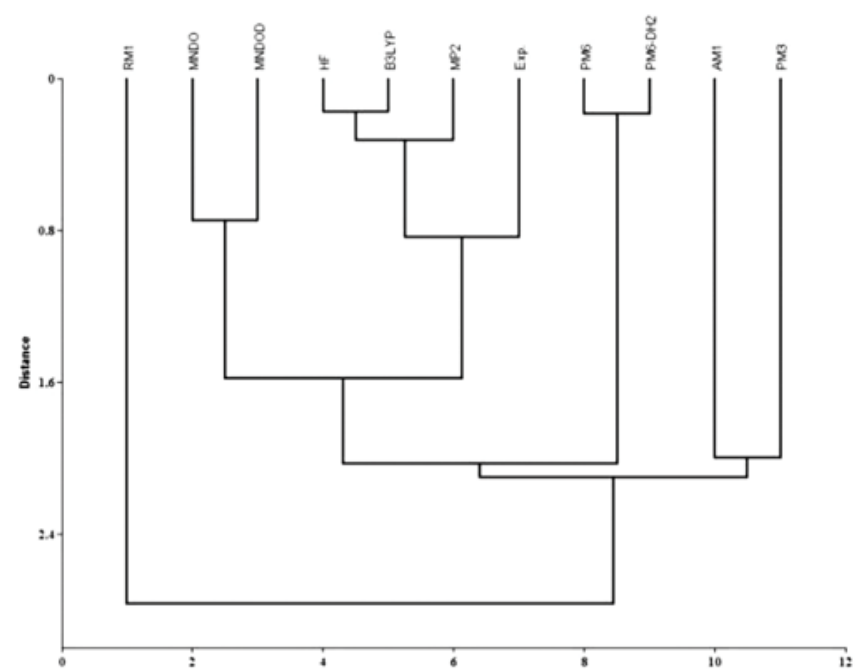

(b)

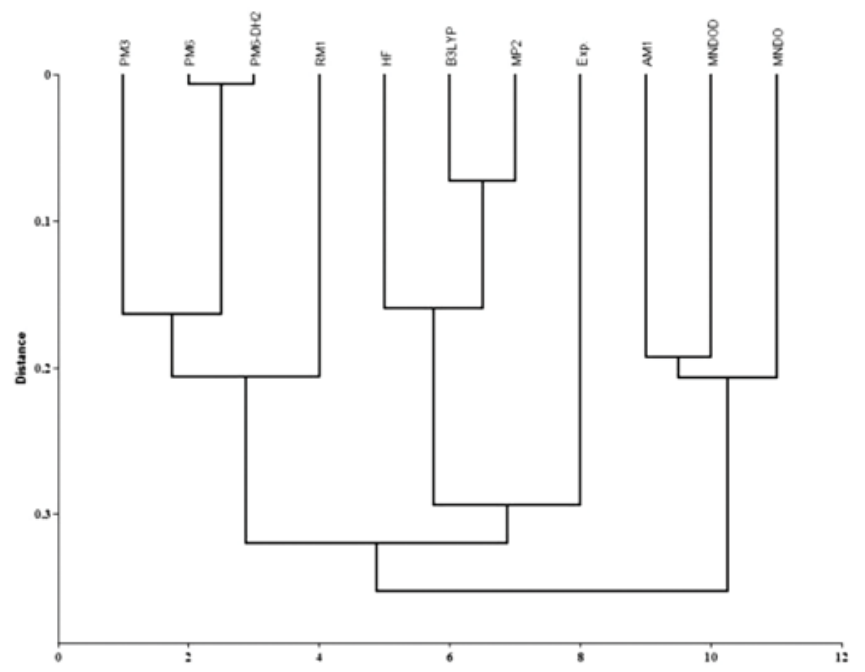

(d)

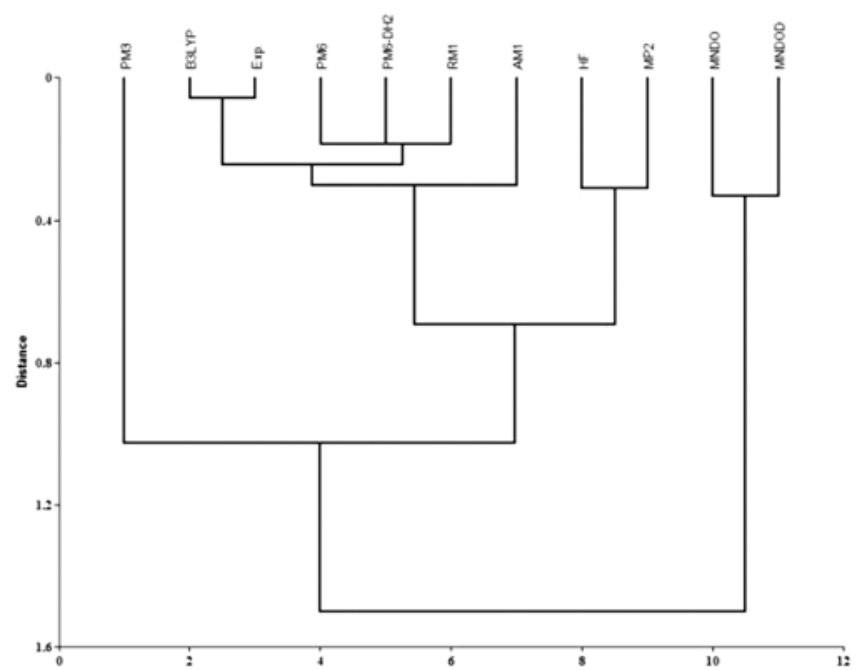

Fig. (5). Dendograms relative to HCA of the Tautomer (1) structure: (a) all geometric parameters are included in the analysis; (b) only bond lengths considered (c) only bond angles considered and (d) only torsional angles considered.

methods for the monomeric and dimeric structures. Analyses were performed in the complete data set and furthermore in three distinct groups: bond lengths, bond angles and torsional angles. Results are shown in Fig. (5). All HCA analysis were made using the PAST program [19].

In an overall view of the performance of the methods, experimental measurements are very similar to the $A b$ Initio and B3LYP estimations. The latter method showed the greatest similarity with the experimental data. This can be noted by the line joining these two branches. With the exception of the torsional angles, in all remaining parameters the experimental values are closer to the high level calculations (HF, MP2 and B3LYP, specially the last method) than the semiempirical calculations, evidencing the superiority of these predictions. In general, RM1, PM6 and PM3 calculations had very similar predictions to each other.

The dendograms referring to torsional angles (Fig. 5d) show the most different pattern in comparison to the other graphics. HF and MP2 predictions, which could not repro- duce the total planarity of this chemical system, were separated from the experimental values, in dendogram. Semiempirical methods seems to give good geometry optimization for the torsional angles.

However, the difficult task of correctly reproducing torsional angles results in considerable changes to the dendograms dedicated only to torsional angles. For example, MP2 method makes good estimates for bond angles and bond distance on this system, but fails to correctly predict torsional angles. The dendograms for torsional angles thus clearly indicate that this method is supplanted by semiempirical predictions.

\section{EXPERIMENTAL}

\subsection{Physical Measurements}

All chemicals and solvents were purchased locally from Aldrich or Fluka. Melting point was determined on a Thomas Hoover Apparatus and is uncorrected. Elemental analysis was performed on a Carlo Erba E-1110. NMR were re- 
corded on a Varian UNITY plus-400 NMR (at $400 \mathrm{MHz}$ for ${ }^{1} \mathrm{H}$ and $100 \mathrm{MHz}$ for ${ }^{13} \mathrm{C}$ ) using TMS as an internal standard. The mass spectrum was measured on a LC-IT-TOF (Shima$\mathrm{dzu}$ ). Chemical shifts are reported in ppm and multiplicities are given as s (singlet), $\mathrm{d}$ (doublet), $\mathrm{t}$ (triplet), $\mathrm{q}$ (quartet), $\mathrm{m}$ (multiplet), dd (double doublet) integration, and coupling constants $(J)$ in hertz.

\subsection{Synthesis}

2-[(3-Phenylsulfanyl-(E)-propylidene)hydrazono]thiazolidin-4-one (ATZ3): Yield (53\%, from ethanol), white crystals, m.p.: $125{ }^{\circ} \mathrm{C}$; m.p.lit $125^{\circ} \mathrm{C}[8] .{ }^{1} \mathrm{H}-$ NMR (400 MHz, DMSO- $\left.d_{6}, \mathrm{ppm}\right): \delta 2.59$ (dd, $2 \mathrm{H}, J=12.2$, $\left.7.0 \mathrm{~Hz}, \mathrm{CH}_{2}\right), 3.18\left(\mathrm{t}, 2 \mathrm{H}, J=7.1 \mathrm{~Hz}, 2 \mathrm{H}, \mathrm{CH}_{2}\right), 3.83(\mathrm{~s}, 2 \mathrm{H}$, $\left.\mathrm{CH}_{2}\right), 7.20(\mathrm{t}, J=6.7 \mathrm{~Hz}, 1 \mathrm{H}, \mathrm{Ar}), 7.27-7.42(\mathrm{~m}, 4 \mathrm{H}, \mathrm{Ar})$, $7.72(\mathrm{t}, 1 \mathrm{H}, J=5.1 \mathrm{~Hz}, \mathrm{CH}=\mathrm{N}), 11.78(\mathrm{~s}, 1 \mathrm{H}, \mathrm{NH}) .{ }^{13} \mathrm{C}-\mathrm{NMR}$ (100 MHz, DMSO- $\left.d_{6}, \mathrm{ppm}\right): \delta 174.71$ (C5), 164.41 (C3), 159.47 (C4), 136.15 (C7), 129.55 (C12, C8), 128.94 (C11, C9), 126.34 (C10), 33.37 (C6), 32.21 (C1), 29.44 (C2). HRMS, Calcd. (Found) for $\mathrm{C}_{12} \mathrm{H}_{13} \mathrm{~N}_{3} \mathrm{OS}_{2}$ : 280.0534 (280.0568).

\subsection{Crystal Structure Determination}

X-ray diffraction data collections were performed on an Enraf-Nonius Kappa-CCD diffractometer (95 mm CCD camera on $\kappa$-goniostat) using graphite monochromated MoK $\alpha$ radiation $(0.71073 \AA)$, at room temperature. Data collections were carried out using COLLECT software [20] up to $50^{\circ}$ in $2 \theta$. Final unit cell parameters were based on 2938 reflections. Integration and scaling of the reflections, correction for Lorentz and polarization effects were performed with the HKL DENZO-SCALEPACK system of programs [21]. Compound structure was solved by direct methods with SHELXS-97 [22]. The models were refined by full-matrix least squares on $\mathrm{F}^{2}$ using SHELXL-97. The program ORTEP-3 [23] was used for graphic representation and the program WINGX [24] to prepare materials for publication. The $\mathrm{H}$ atom bound to N3 was located in a difference Fourier map and refined freely with isotropic displacement parameter. All other $\mathrm{H}$ atoms were located by geometric considerations placed $(\mathrm{C}-\mathrm{H}=0.93-0.98 \AA)$ and refined as riding with $\mathrm{U}_{\text {iso }}(\mathrm{H})=1.5 \mathrm{U}_{\text {eq }}\left(\mathrm{C}\right.$-methyl) or $1.2 \mathrm{U}_{\text {eq }}$ (other). An Ortep-3 diagram of the molecule is shown in Fig. (2), while in Table $\mathbf{1}$ shown the main crystallographic parameters.

\subsection{Quantum Chemistry Calculations and Statistical and Chemometric Evaluation of the Results}

In order to ensure the accuracy and reliability of the proposed X-ray structures, a quantum chemical investigation at Semiempirical, $A b$ initio and Density Functional Theory (DFT) levels was made about the structures and energies of the monomeric and dimeric structures proposed in this work. Concerning the semiempirical methods a broad set of parameterizations was used ranging from the most traditional based in NDDO approximation, such as AM1, MNDO and PM3, to the more recent and accurate implementations as RM1 [25], MNDO/d [26], PM6 [27]. Each of these methods is encoded in the MOPAC 2009 program [28]. Hartree-Fock (HF), Second Order Møller-Plesset (MP2) and DFT (via B3LYP func- tional) calculations were carried out in the Gaussian 03 program[29] using 6-31 $\mathrm{G}^{* *}$ basis sets for $\mathrm{C}, \mathrm{H}, \mathrm{N}$ and $\mathrm{O}$ atoms and $6-31+G^{*}$ for $S$ atom. Semiempirical calculations of geometry optimization and energy had their precision improved by the inclusion of GNORM $=0.01$ and PRECISE keywords. Gaussian 03 default criteria were kept throughout this work. Optimized geometries obtained by quantum chemical methods had their performance evaluated through statistical and chemometric methods. In addition to common statistical indexes such as: average error (AE), average unsigned error (AUE) and standard deviation (SD), a Hierarchic Cluster Analysis (HCA) was carried out in the calculated geometric parameters generated by the quantum chemical methods. HCA is a chemometric technique of pattern recognition, where similarities between clusters are estimated by a distance measurement. A common approach for this method is to initially treat each data as a cluster and join each closer cluster together. This process is repeated until only one cluster remains. The information obtained in this procedure is shown in a two-dimensional plot called a dendogram [30]. The numerical data used in HCA was initially submitted to an autoscaling preprocessing. This process becomes indispensable, due to the different units from the geometric parameters studied in this analysis (bond lengths in angstroms; bond and torsional angles in degrees). The autoscaling applied in all data sets consisted in subtracting each class of geometric parameter from its average and then divided by its standard deviation. The average and standard deviation were calculated for each class of parameter and quantum chemical method or experimental data. This preprocessed data formed the matrix of elements, where the columns are occupied by the geometric parameters and rows contain the results produced for each method. Quantumchemical calculations of geometry optimization are made considering the molecule isolated from the others one or solvent. Geometries of molecules in crystals are typically not necessarily the same as those of isolated molecules. In the crystalline phase, the molecules are under influence of the intermolecular interactions and crystal packing forces. However, comparisons of bond lengths and angles between gasand solid-phase structures suggest that these influences are likely to be typically small. It is not the case concerning conformations (torsion angles), which may be much greater, leading to the possibility that overall molecular shape may differ significantly between the gas and crystalline phases. Since accurate gas-phase structure determinations are usually restricted to very small molecules, comparison between the quantum chemical methods and crystalline structures shows to be a useful method to study the agreement between theoretical and experimental estimations [31].

\section{CONCLUSION}

In summary, we disclosed the entire molecular structure of the 2 [(2-phenylthioethylidene)-hydrazono]-thiazolidin-4one (ATZ3) by X-ray analysis allied with semiempirical and quantum chemical calculations.

Quantum chemical investigations confirmed, through energetics and structural evidences, the X-ray structure proposed. Statistical analysis of the errors and standard deviations, as well as the relative energies from the other possible 
tautomers, support the quality of the proposed X-ray structure. The theoretical investigations show the importance of the semiempirical methods, as an alternative exploratory tool for similar chemical systems, in comparison to the excessive computational demand of $A b$ Initio and DFT methods performing the same tasks. Among the high level quantum chemistry methods, the B3LYP had the best performance, combining reasonably well the inclusion of electronic correlation and computational demand. B3LYP proved to better predict geometries than the typically more precise MP2 method.

The use of HCA approach allowed a panoramic and multivariate view of the performance obtained with the computational methods, regarding the predictivity of the geometry of ATZ3 system.

\section{CONFLICT OF INTEREST}

The authors confirm that this article content has no conflict of interest.

\section{ACKNOWLEDGEMENTS}

This study received support from the Brazilian National Research Council (CNPq, grant number 479982/2008-2). M.V.O.C. holds FACEPE for researcher scholarship (BFP).

\section{SUPPLEMENTARY MATERIALS}

Crystallographic data for compound ATZ3 have been deposited with the Cambridge Crystallographic Data Center as Supplementary Publication No. CCDC 913377. Copies of the data can be obtained, free of charge, by application to CCDC, 12 Union Road, Cambridge CH21EZ, UK (fax: +44 1223336033 or e-mail: deposit@ccdc.cam.ac.uk). Structural data, statistical estimations and relative energies calculated through quantum chemical methods are enclosed in the supplementary pages.

Supplementary material is available on the publisher's web site along with the published article.

\section{REFERENCES}

[1] Bondock, S.; Khalifa, W.; Fadda, A. A. Synthesis and Antimicrobial Evaluation of Some New Thiazole, Thiazolidinone and Thiazoline Derivatives Starting from 1-Chloro-3,4Dihydronaphthalene-2-Carboxaldehyde. Eur. J. Med. Chem. 2007, $42,948-954$.

[2] Küçükgüzel, G.; Kocatepe, A.; De Clercq, E.; Sahin, F.; Güllüce, M. Synthesis and Biological Activity of 4-Thiazolidinones, Thiosemicarbazides Derived from Diflunisal Hydrazide. Eur. J. Med. Chem. 2006, 41, 353-359.

[3] Saiz, C.; Pizzo, C.; Manta, E.; Wipf, P.; Mahler, S. G. Microwave Assisted Tandem Reactions for the Synthesis of 2-Hydrazolyl-4Thiazolidinones. Tetrahedron Lett. 2009, 50, 901-904.

[4] Moreira, D. R. M.; Costa, S. P. M.; Hernandes, M. Z.; Rabello, M. M.; de Oliveira Filho, G. B.; de Melo, C. M. L.; da Rocha, L. F.; de Simone, C. A.; Ferreira, R. S.; Fradico, J. R. B.; Meira, C. S.; Guimarães, E. T.; Srivastava, R. M.; Pereira, V. R. A.; Soares, M. B. P.; Leite, A. C. L. Structural Investigation of Anti-Trypanosoma Cruzi 2-Iminothiazolidin-4-Ones Allows the Identification of Agents with Efficacy in Infected Mice. J. Med. Chem. 2012, 55, 10918-10936.
Tenório, R. P.; Lima, J. G. De; Faria, A. R. De; Alves, A. J. Tiossemicarbazonas: Métodos De Obtenção, Aplicações Sintéticas e Importância Biológica. Quim. Nov. 2005, 28, 1030-1037.

[6] De Oliveira Cardoso, M. V.; de Siqueira, L. R. P.; da Silva, E. B.; Costa, L. B.; Hernandes, M. Z.; Rabello, M. M.; Ferreira, R. S.; da Cruz, L. F.; Magalhães Moreira, D. R.; Pereira, V. R. A.; de Castro, M. C. A. B.; Bernhardt, P. V.; Leite, A. C. L.; Moreira, D. R. de M.; Cardoso, M. V. de O.; Alves Pereira, V. R.; Silva, R. O.; Kiperstok, A. C.; Lima, M. da S.; Soares, M. B. P. 2-Pyridyl Thiazoles as Novel Anti-T. Cruzi Agents: Structural Design, Synthesis and Pharmacological Evaluation. Eur. J. Med. Chem. 2014, 86, 48-59.

[7] Véniant, M. M.; Hale, C.; Hungate, R. W.; Gahm, K.; Emery, M. G.; Jona, J.; Joseph, S.; Adams, J.; Hague, A.; Moniz, G.; Zhang, J.; Bartberger, M. D.; Li, V.; Syed, R.; Jordan, S.; Komorowski, R.; Chen, M. M.; Cupples, R.; Kim, K. W.; St Jean, D. J.; Johansson, L.; Henriksson, M. A.; Williams, M.; Vallgårda, J.; Fotsch, C.; Wang, M. Discovery of a Potent, Orally Active 11 betaHydroxysteroid Dehydrogenase Type 1 Inhibitor for Clinical Study: Identification of (S)-2-((1S,2S,4R)-bicyclo[2.2.1]heptan-2Ylamino)-5-Isopropyl-5-Methylthiazol-4(5H)-One (AMG 221). $J$. Med. Chem. 2010, 53, 4481-4487.

[8] Lima Leite, A. C.; Santos, L. M. F.; Barbosa, F. F.; de Oliveira Cardoso, M. V; Moreira, D. R. M.; de Souza, I. A. Synthesis of Aminoacyl Thiaolidones as Potential Antitumour Agents. Biomed. Pharmacother. 2006, 60, 121-126.

[9] Leite, A. C. L.; Moreira, D. R. de M.; Cardoso, M. V. de O. Hernandes, M. Z.; Alves Pereira, V. R.; Silva, R. O.; Kiperstok, A. C.; Lima, M. da S.; Soares, M. B. P. Synthesis, Cruzain Docking, and in Vitro Studies of Aryl-4-Oxothiazolylhydrazones against Trypanosoma Cruzi. ChemMedChem 2007, 2, 1339-1345.

[10] Donnici, C. L.; Araújo, M. H.; Oliveira, H. S.; Moreira, D. R. M.; Pereira, V. R. A.; de Assis Souza, M.; de Castro, M. C. A. B.; Leite, A. C. L. Ruthenium Complexes Endowed with Potent AntiTrypanosoma Cruzi Activity: Synthesis, Biological Characterization and Structure-Activity Relationships. Bioorg. Med. Chem. 2009, 17, 5038-5043.

[11] Hernandes, M. Z.; Rabello, M. M.; Leite, A. C. L.; Cardoso, M. V. O.; Moreira, D. R. M.; Brondani, D. J.; Simone, C. A.; Reis, L. C.; Souza, M. A.; Pereira, V. R. A.; Ferreira, R. S.; McKerrow, J. H. Studies toward the Structural Optimization of Novel Thiazolylhydrazone-Based Potent Antitrypanosomal Agents. Bioorg. Med. Chem. 2010, 18, 7826-7835.

[12] Moreira, D. R. M.; Lima Leite, A. C.; Cardoso, M. V. O.; Srivastava, R. M.; Hernandes, M. Z.; Rabello, M. M.; da Cruz, L. F.; Ferreira, R. S.; de Simone, C. A.; Meira, C. S.; Guimaraes, E. T.; da Silva, A. C.; Dos Santos, T. A. R.; Pereira, V. R. A.; Pereira Soares, M. B. Structural Design, Synthesis and Structure-Activity Relationships of Thiazolidinones with Enhanced AntiTrypanosoma Cruzi Activity. ChemMedChem 2014, 9, 177-188.

[13) Ostapiuk, Y. V.; Obushak, M. D.; Matiychuk, V. S.; Naskrent, M.; Gzella, A. K. A Convenient Method for the Synthesis of 2-[(5Benzyl-1,3-Thiazol-2-Yl)imino]-1,3-Thiazolidin-4-One

Derivatives. Tetrahedron Lett. 2012, 53, 543-545.

[14] Al-Zaydi, K. M.; Ostapiuk, Y. V.; Obushak, M. D.; Matiychuk, V. S.; Naskrent, M.; Gzella, A. K. A Study of the Reaction of 2Thiazolin-4-Ones with Some Electrophiles under Microwave Irradiation versus Conventional Condition. Tetrahedron Lett. 2010, $14,543-545$

[15] Klika, K. D.; Balentová, E.; Bernát, J.; Imrich, J.; Vavrušová, M.; Pihlaja, K.; Koch, A.; Kleinpeter, E.; Kelling, A.; Schilde, U. Structural Revision of Products Resulting from the Reaction of Methylhydrazine with Acridin-9-Y1 Isothiocyanate due to Unexpected Acridinyl Migration and Further Reactions. ARKIVOC 2006, $x v i, 93-108$.

[16] Karabatsos, G. J.; Vane, F. M.; Taller, R. A.; Hsi, N.; Karabatsos, J. Structural Studies by Nuclear Magnetic Resonance . J. Am. Chem. Soc. 1964, 86, 3351-3357.

[17] Allen, F. H. The Cambridge Structural Database: A Quarter of a Million Crystal Structures and Rising. Acta Crystallogr. Sect. B Struct. Sci. 2002, 58, 380-388.

[18] Kiralj, R.; Ferreira, M. M. C. Combined Computational and Chemometric Study of 1H-Indole-3-Acetic Acid. Int. J. Quantum Chem. 2003, 95, 237-251. 
[19] Hammer, O.; Harper, D. A. T.; Ryan, P. D. Past: Paleontological Statistics Software Package for Education and Data Analysis. Paleontol. Electron. 2001, 4, 1-9.

[20] Nonius, B. V. Enraf-Nonius COLLECT.

[21] Otwinowski, Z.; Minor, W. Methods in Enzymology. Macromol. Crystallogr. Part A 1997, 276, 307-326.

[22] Sheldrick, G. SHELXL-97 and SHELXS-97, Program for X-Ray Crystal Structure Solution and Refinement. Univ. Göttingen 1997.

[23] Farrugia, L. J. ORTEP -3 for Windows - a Version of ORTEP -III with a Graphical User Interface [GUI). J. Appl. Crystallogr. 1997, $30,565-565$.

[24] Farrugia, L. J. WinGX Suite for Small-Molecule Single-Crystal Crystallography. J. Appl. Crystallogr. 1999, 32, 837-838.

[25] Rocha, G. B.; Freire, R. O.; Simas, A. M.; Stewart, J. J. P. RM1: A Reparameterization of AM1 for H, C, N, O, P, S, F, Cl, Br, and I. J. Comput. Chem. 2006, 27, 1101-1111.

[26] Thiel, W.; Voityuk, A. A. Extension of the MNDO Formalism Tod Orbitals: Integral Approximations and Preliminary Numerical Results. Theor. Chim. Acta 1992, 81, 391-404.

[27] Stewart, J. J. P. Optimization of Parameters for Semiempirical Methods V: Modification of NDDO Approximations and Application to 70 Elements. J. Mol. Model. 2007, 13, 1173-1213.

[28] Stewart, J. J. P. mopac2009, 2009.
[29] Frisch, M.; Trucks, G.; Schlegel, H.; Scuseria, G.; Robb, M.; Cheeseman, J.; Montgomery, J.; Vreven, T.; Kudin, K.; Burant, J.; Millam, J.; Iyengar, S.; Tomasi, J.; Barone, V.; Mennucci, B.; Cossi, M.; Scalmani, G.; Rega, N.; Petersson, G.; Nakatsuji, H.; Hada, M.; Ehara, M.; Toyota, K.; Fukuda, R.; Hasegawa, J.; Ishida, M.; Nakajima, T.; Honda, Y.; Kitao, O.; Nakai, H.; Klene, M.; Li, X.; Knox, J.; Hratchian, H.; Cross, J.; Bakken, V.; Adamo, C.; Jaramillo, J.; Gomperts, R.; Stratmann, R.; Yazyev, O.; Austin, A.; Cammi, R.; Pomelli, C.; Ochterski, J.; Ayala, P.; Morokuma, K.; Voth, G.; Salvador, P.; Dannenberg, J.; Zakrzewski, V.; Dapprich, S.; Daniels, A.; Strain, M.; Farkas, O.; Malick, D.; Rabuck, A.; Raghavachari, K.; Foresman, J.; Ortiz, J.; Cui, Q.; Baboul, A.; Clifford, S.; Cioslowski, J.; Stefanov, B.; Liu, G.; Liashenko, A.; Piskorz, P.; Komaromi, I.; Martin, R.; Fox, D.; Keith, T.; Laham, A.; Peng, C.; Nanayakkara, A.; Challacombe, M.; Gill, P.; Johnson, B.; Chen, W.; Wong, M.; Gonzalez, C.; Pople, J. Gaussian 03, Revision C.02.

[30] Beebe, K. R.; Pefl, R. J.; Seasholtz, M. B. Chemometrics: A Practical Guide; John Wiley \& Sons, 1998.

[31] Sensato, F. R.; Custodio, R.; Cass, Q. B.; Longo, E.; Hernandes, M. Z.; Longo, R. L.; Andrés, J. The Use of the Generator Coordinate Method for Designing Basis Set. Application to Oxo-Diperoxo Molybdenum Complexes. J. Mol. Struct. THEOCHEM 2002, 589590, 251-264. 